\title{
Development of Guidance Techniques for Regional Anesthesia: Past, Present and Future
}

\section{Zehao Wu (D \\ Yun Wang (D)}

Department of Anesthesiology, Beijing Chaoyang Hospital, Capital Medical University, Beijing, 100020, People's Republic of China
Correspondence: Yun Wang

Department of Anesthesiology, Beijing Chaoyang Hospital, Capital Medical

University, No. 8 Gongti South Road,

Chaoyang District, Beijing, People's

Republic of China

Tel +86-1352161/1825

Email wangyun129@ccmu.edu.cn

\begin{abstract}
Regional anesthesia has been widely used in clinical practice. Over the past 30 years, various guidance techniques have been developed for regional anesthesia ranging from paresthesia progressing to neurostimulation and currently ultrasound guidance. Especially, the use of point-of-care ultrasound greatly enhances the success rate of regional anesthesia. However, the poor imaging quality of ultrasound in patients with obesity, fat infiltration, etc., limits the use of ultrasound. The combined use of ultrasound with neurostimulator, electromyography, pressure monitoring, etc. is advocated in order to facilitate regional anesthesia in this cohort of patients. The accumulated evidence has shown that the ultrasound combined with other techniques (UCOT) can help to solve the difficulties of puncture location caused by obesity, anatomical variation, and other factors when using ultrasound guidance alone. In recent years, with the development of medical image fusion and medical image artificial intelligence identification technology, guidance techniques for regional anesthesia have advanced considerably. To understand the advantages and disadvantages of the various guidance techniques for regional anesthesia developed in recent years and to guide their rational clinical application, this paper reviews these techniques, describing the progression from the early use of paresthesia to the latest UCOT, as well as the latest research on UCOT, and the prospects for the development of new guidance techniques for regional anesthesia.
\end{abstract}

Keywords: guidance, neurostimulation, ultrasound, regional anesthesia, artificial intelligence

\section{Introduction}

Compared with the conventional nerve block method using anatomical localization and paresthesia, localization using neurostimulation is more accurate, objective, and safer. ${ }^{1}$ However, neurostimulator guidance operates blindly and there is a high failure rate in patients with anatomical variations. Ultrasound can provide more intuitive and accurate nerve location, clarify the relative positions of blood vessels, nerves, and muscles around the puncture site, provide real-time images when blocking the target nerve, and monitor the diffusion of local anesthetics in realtime to achieve accurate anesthesia. ${ }^{2}$ In recent years, with the application of computer techniques in medical imaging, it has been possible to combine ultrasound and artificial intelligence (AI) with medical image fusion, which can be applied to guide the nerve block, allowing the development of sophisticated guidance techniques for nerve block (denoted as the ultrasound combined with other techniques (UCOT)). These techniques have produced excellent preliminary results 
in the clinic. However, the success rate, operation time and patient comfort of all regional block anesthesia depend on the operator, and the results achieved by operators with different seniority and proficiency are not the same, which is the main limitation addressed by the relevant studies. ${ }^{3,4}$ This paper reviews the advantages, disadvantages, and clinical applications of both the conventional and latest guidance techniques for regional anesthesia (Figure 1).
Regional Anesthesia Guided by the Paresthesia or Neurostimulation Advantages of Nerve Block Guidance by Neurostimulation Compared with

Paresthesia

The use of neurostimulation increases the nerve block success rate and reduces the blocking time compared

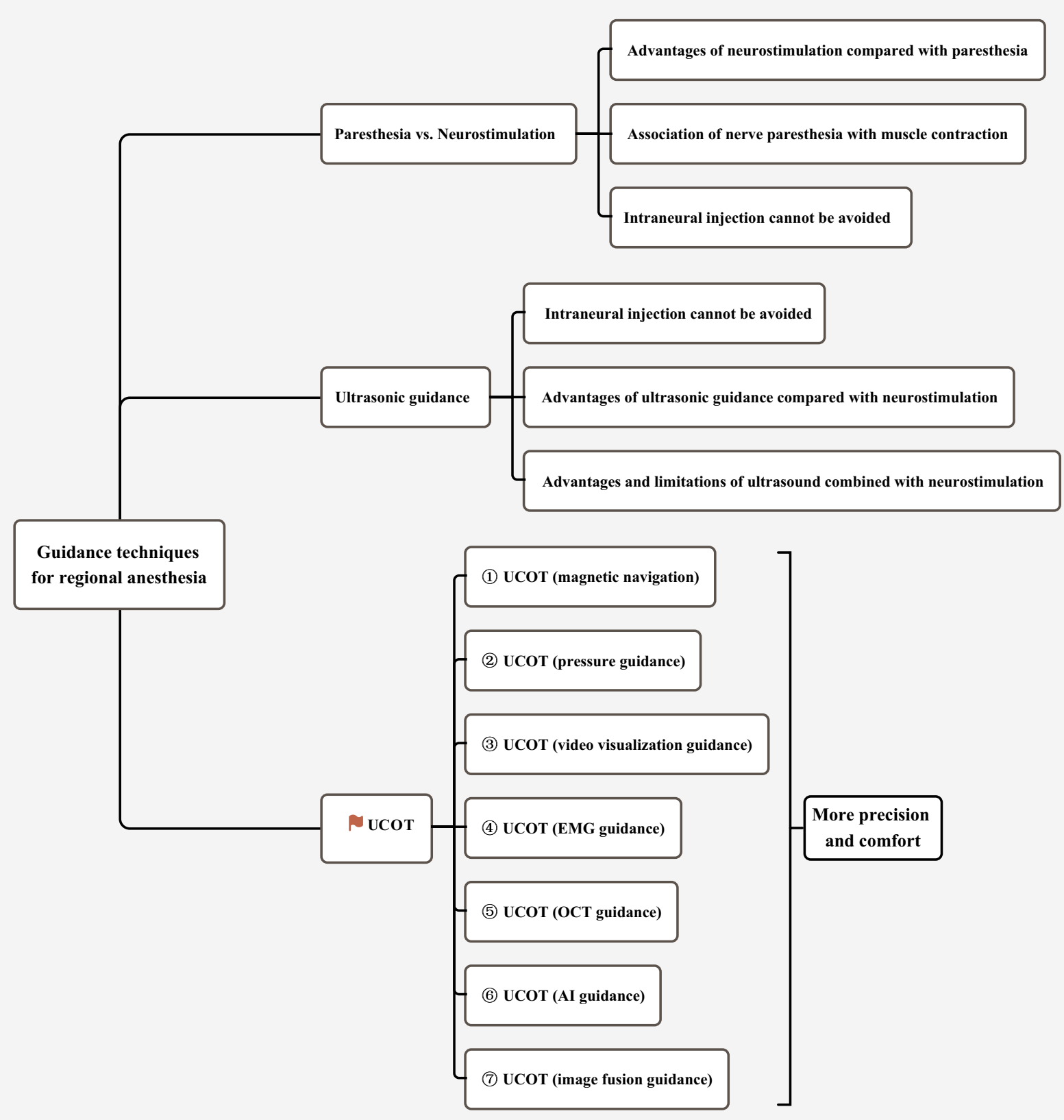

Figure I Diagram of advances in the guidance techniques for regional anesthesia.

Abbreviations: UCOT, ultrasound combined with other techniques; EMG, electromyography; OCT, optical coherence tomography; Al, artificial intelligence. 
Table I Comparison of Advantages of Various Guidance Methods for Nerve Block

\begin{tabular}{|c|c|c|}
\hline Comparison (">> Stands for Better) & $\begin{array}{l}\text { Related } \\
\text { Studies }\end{array}$ & Advantage \\
\hline \multirow[t]{2}{*}{ Neurostimulation $>$ Paresthesia } & Sia $2000^{5}$ & High success rate of block and short onset time of block \\
\hline & Che $2005^{7}$ & Short onset of block and high patient comfort \\
\hline US guidance $>$ Neurostimulation & $\begin{array}{l}\text { Xu } 2018^{22} \\
\text { He } 2011^{23} \\
\text { Li } 2017^{24}\end{array}$ & $\begin{array}{l}\text { The onset time of block is short and the dosage of local anesthetics is } \\
\text { small } \\
\text { High success rate of block } \\
\text { The onset time of block is short, with few complications and long duration } \\
\text { of block }\end{array}$ \\
\hline Neurostimulation $>$ US guidance & $\begin{array}{l}\text { Franco } 200 \mathrm{I}^{25} \\
\text { Vester-Andersen } \\
1986^{26}\end{array}$ & $\begin{array}{l}\text { High success rate of block } \\
\text { High success rate of block }\end{array}$ \\
\hline UCOT (magnetic navigation) > US guidance & Tang $2012^{32}$ & $\begin{array}{l}\text { Short block time, low puncture risk, avoid the influence of surrounding } \\
\text { organs and blood vessels }\end{array}$ \\
\hline UCOT (pressure guidance) > US guidance & Li $2020^{37}$ & High success rate of block, widening the visual measurement range \\
\hline $\begin{array}{l}\text { UCOT (video visualization guidance) }>\text { US } \\
\text { guidance }\end{array}$ & Kasuya $2017^{41}$ & High success rate of block \\
\hline $\begin{array}{l}\text { UCOT (electromyography guidance) }>\text { US } \\
\text { guidance }\end{array}$ & $\begin{array}{l}\text { Mullins } 2017^{46} \\
\text { Hodes } 1948^{48} \\
\text { Qian } 2020^{49}\end{array}$ & $\begin{array}{l}\text { High success rate of block } \\
\text { High success rate of block } \\
\text { The position of the puncture needle more accurate and the operation of } \\
\text { nerve block safer }\end{array}$ \\
\hline $\begin{array}{l}\text { UCOT (optical coherence tomography } \\
\text { guidance) > US guidance }\end{array}$ & $\begin{array}{l}\text { Tang } 2015^{51} \\
\text { Raphael } 2007^{53}\end{array}$ & $\begin{array}{l}\text { The position of the puncture needle more accurate and have lower risks } \\
\text { The position of the puncture needle more accurate and have lower risks }\end{array}$ \\
\hline UCOT $($ Al guidance) $>$ US guidance & $\begin{array}{l}\text { Bernards } 2008^{31} \\
\text { Liu } 2018^{57}\end{array}$ & $\begin{array}{l}\text { The position of the puncture needle more accurate and the operation of } \\
\text { nerve block safer } \\
\text { The position of the puncture needle more accurate and the operation of } \\
\text { nerve block safer }\end{array}$ \\
\hline UCOT (image fusion guidance) > US guidance & $\begin{array}{l}\text { Strid } 2017^{61} \\
\text { Munirama } 2016^{62}\end{array}$ & $\begin{array}{l}\text { The position of the puncture needle more accurate and the operation of } \\
\text { nerve block safer } \\
\text { Effectively reduce the incidence of intraneural injection }\end{array}$ \\
\hline
\end{tabular}

Abbreviations: US, ultrasound; UCOT, ultrasound combined with other techniques; Al, artificial intelligence.

with conventional paresthesia guidance. Sia et $\mathrm{al}^{5,6}$ compared the difference between paresthesia guidance and neurostimulation guidance in brachial plexus block. The results showed that the neurostimulation group was superior to the paresthesia group in the success rate $(91 \%$ vs $76 \%$, respectively) and onset time of the block. Additionally, in a three-point axillary brachial plexus block, nerve block guided by neurostimulation can shorten the block onset time and the waiting time for surgeons, which is helpful for emergency surgery and patient satisfaction as well as reducing the discomfort of a tourniquet.
This is related to the high accuracy of localization and more effective musculocutaneous nerve block ${ }^{7,8}$ (Table 1).

\section{Association of Nerve Paresthesia Induced by Landmark-Guided Puncture with the Motor Response Induced by Neurostimulation}

Urmey et $\mathrm{al}^{9}$ reported that, of 30 patients who received nerve paresthesia induced by the conventional landmark-guided puncture with an interscalene brachial plexus block and subsequent neurostimulation, only $30 \%$ had a motor response 
under $1 \mathrm{~mA}$ while all patients experienced a successful block. It indicates that the lack of motor response cannot exclude the possibility of nerve-needle touch. Choyce et $\mathrm{al}^{10}$ in a similar study, found that $30 \%$ of patients had the separation of paresthesia and motor response in axillary brachial plexus blocks. Hence, the nerve electrical stimulation does not necessarily produce the motor response when patients have the nerve paresthesia during the landmark-guided nerve block procedure. On the contrary, in the process of neurostimulationguided nerve block, patients may not experience the nerve paresthesia in the presence of motor response produced by nerve stimulation.

\section{Neither Nerve Paresthesia nor Neurostimulation Guidance Technique Can Avoid the Intraneural Injection}

Selander et $\mathrm{al}^{11}$ believed that paresthesia occurrence during nerve block may lead to the increased risk of nerve injury after nerve block. Previous studies have shown that intraneural injection occurs frequently in conventional paresthesiaguided block. The closer the puncture needle is to the nerve, the stronger the paresthesia. Because of differences in sensory thresholds and anatomical variations, it is often difficult to determine the exact positioning of the needle and thus, intraneural injection may occur. Proponents of neurostimulationguided nerve block believe that the use of this technique can reduce the risk of nerve injury. They consider that if neurostimulator is used, the blocking needle can trigger a corresponding muscle contraction before touching the nerve, and then the further advancement of needle can be avoided. $^{12}$ However, Choyce et $\mathrm{al}^{10}$ have questioned this view. They considered that although the $0.5 \mathrm{~mA}$ to be a reasonable threshold for the use of neurostimulation, it was unknown whether the intraneural injection happened below this threshold. Mulroy and Mitchell ${ }^{13}$ also reported that four patients experienced inadvertent paresthesia during neurostimulation guidance, indicating that the use of neurostimulation cannot always avoid the contact between puncture needle tip and nerve. Robards et $\mathrm{al}^{14}$ found that in 24 patients undergoing ultrasound-guided sciatic nerve block for knee surgery, 20 $(83.3 \%)$ had a motor response only when the puncture needle was inserted into the nerve, while the remaining four $(16.7 \%)$ had no motor response when the puncture needle was inserted into the nerve with the stimulation current adjusted to $1.5 \mathrm{~mA}$. The intraneural injections occurred in patients who experienced motor responses under a stimulation current of 0.2 $-0.4 \mathrm{~mA}$. All 24 patients were fully anesthetized without
Table 2 All of Nerve Block Guidance Methods Do Not Avoid the Occurrence of Intraneural Injection

\begin{tabular}{|l|l|}
\hline $\begin{array}{l}\text { Following Nerve Block Guidance } \\
\text { Methods Do Not Avoid Intraneural } \\
\text { Injection }\end{array}$ & Related Studies \\
\hline Paresthesia & $\begin{array}{l}\text { Selander } 1977^{11} \\
\text { Choyce } 2001^{10}\end{array}$ \\
\hline Neurostimulation & $\begin{array}{l}\text { Mulroy and } \\
\text { Mitchell } 2002^{13} \\
\text { Robards } 2009^{14} \\
\text { Sala Blanch } 2011^{15}\end{array}$ \\
\hline US guidance & $\begin{array}{l}\text { Liu } 2011^{18} \\
\text { Liu 2009 } \\
\text { Neal } 2010^{20} \\
\text { Chin } 2008^{21}\end{array}$ \\
\hline US combined with neurostimulation & Barrington $2009^{27}$ \\
\hline
\end{tabular}

Abbreviation: US, ultrasound.

postoperative neurological dysfunction. These results indicate that neurostimulation guidance cannot prevent intraneural injection.

Sala Blanch et $\mathrm{al}^{15}$ found that the cross-sectional area of the sciatic nerve in the popliteal fossa changed after intraneural injection using ultrasound and computed tomography (CT) scanning but no nerve dysfunction was found in clinical and electrophysiological studies. This indicates that intraneural injection occurring during neurostimulation-guided sciatic nerve block may not lead to clinical nerve injury. Although the above reports of Robards et $\mathrm{al}^{14}$ and Sala Blanch et $\mathrm{al}^{15}$ showed that intraneural injection did not lead to postoperative neurological dysfunction, the risk of neurological dysfunction in some high-risk patients (such as diabetic patients) cannot be ruled out. Kirchmair et al $^{16}$ demonstrated that the amplitude of the compound muscle action potential was significantly decreased after nerve injury by acupuncture or intraneural injection, which was found to be due to nerve conduction block caused by myelin sheath rupture or axon loss (Table 2).

\section{Ultrasonic Guidance for Regional Anesthesia \\ The Ultrasound Guidance Technique \\ Cannot Avoid the Intraneural Injection}

Neurostimulation alone cannot reduce the incidence of nerve injury. Theoretically, ultrasonic guidance for peripheral nerve block can display the relative positions of the nerve and needle tip more intuitively as well as being able to observe dynamic 
changes in the local anatomical structure after drug injection, which can contribute to the avoidance of nerve injury. ${ }^{17}$ However, some studies have found that ultrasound-guided nerve block cannot avoid intraneural injection entirely ${ }^{18}$ and thus cannot reduce the incidence of postoperative nerve injury effectively. ${ }^{19,20}$ The reasons are as follows: first, the resolution of portable ultrasound machine is not yet able to distinguish the perineurium, so the perineurium injury cannot be avoided. Second, nerves on ultrasonic images may not display adequately in some patients, resulting in fuzzy and poor-quality images. Third, the scanning skills of different operators can also affect the ultrasound image quality.

In addition, the intraneural injection during ultrasoundguided nerve block may not necessarily lead to nerve injury. Chin et $\mathrm{al}^{21}$ have shown that ultrasonic observation of nerve expansion after intraneural injection does not represent permanent functional damage to the nerve. In conclusion, ultrasound-guided and neurostimulation-guided nerve block cannot completely avoid intraneural injection, and intraneural injection may not necessarily lead to nerve injury (Table 2).

\section{Advantages of Ultrasound Guidance Compared with Neurostimulation Guidance}

Previous studies have compared the advantages and disadvantages of neurostimulation guidance and ultrasound guidance in brachial plexus block and found that the onset time of sensory and motor block using ultrasound guidance was shorter than that of neurostimulation guidance. $^{22}$ The reason may be that we can clearly see the location of the target nerve, the local anesthetic injection site, and the diffusion around the nerve in the ultrasonic image. Another advantage of ultrasound-guided brachial plexus block is a reduction in the amount of local anesthetic used. In addition, studies have found that when patients have musculoskeletal system abnormalities, the use of a neurostimulator may fail due to anatomical variation. Compared with neurostimulation, ultrasound guidance can significantly increase the success rate of nerve block in patients with malformations. Ultrasound and neurostimulator positioning technology can complement each other. ${ }^{23}$ The latest study shows that in brachial plexus blocks in obese patients, nerve blocks using ultrasound guidance had shorter onset times, longer duration, better anesthetic effects, lower incidence of complications, and should be safer in the clinic than the use of a neurostimulator or the conventional landmark-guided method. ${ }^{24}$ However, some studies from the end of the last century to the beginning of this century held the opposite view, and Franco et $\mathrm{al}^{25}$ and Vester-Andersen et $\mathrm{al}^{26}$ showed that the success rate of using neurostimulation was more than $95 \%$ compared with ultrasound-guided (Table 1).

\section{Advantages and Limitations of Regional Blocks Under Ultrasound and Neurositimulation Guidance}

The combined application of ultrasound and neurostimulation to block specific nerves makes the procedure effective and safe. The advantages are as follows: first, the combination of ultrasound and neurostimulation can result in a better blocking effect and success rate in patients with anatomical variations. Second, the combination of ultrasound and neurostimulation can help to identify the nerve when the nerve is unclear under ultrasound imaging alone. Third, the combined guidance can avoid the trauma caused by multiple punctures under neurostimulation guidance alone.

Although ultrasound combined with neurostimulationguided nerve block has many advantages, it cannot entirely avoid postoperative nerve injury. Barrington et $\mathrm{al}^{27}$ analyzed the data of more than 8000 patients with peripheral nerve block. They found that the use of ultrasound guidance, neurostimulation guidance, or a combination of the two had no significant effect on the incidence of nerve injury, and there was no significant difference between the incidence of long-term nerve injury observed in that survey and similar reports from the previous decade. It is difficult to avoid nerve injury using ultrasound alone. Timely and effective detection misplacement of puncture needle into nerve remains an ongoing clinical problem. Some studies have attempted to judge the relative positions of the needle tip and the nerve by comparing changes in the electric resistance of puncture needle. Tsui et $\mathrm{al}^{28}$ found that the electric resistances of the insulated puncture needle in and out of the nerve were significantly different whether the nerve was punctured under ultrasonic guidance or directly exposed. The electric resistance of the puncture needle outside the nerve was less than that of the puncture needle inside the nerve, and the difference was statistically significant. This conclusion suggests that the position of the needle tip can be determined by monitoring the needle body resistance with the neurostimulator, and the combination with ultrasound guidance could avoid the 
injection of drugs into the nerve. Additionally, awareness of resistance changes during injection and keeping the patient awake during the nerve block procedure are also considered to be effective means of avoiding avoid nerve injury ${ }^{29-31}$ (Table 2).

\section{UCOT for Regional Anesthesia}

Ultrasound resolution is poor for some deep structures. In addition, when ultrasonic guidance is used for in-plane or out-of-plane punctures, it is often unable to correctly determine the accurate position of the puncture needle tip. Therefore, ultrasound should be combined with other emerging technologies to further improve the accuracy and reduce the incidence of complications (Table 1).

\section{UCOT (Magnetic Navigation)}

Although ultrasonic guidance nerve block has many advantages, it also has some disadvantages, including difficulty in displaying the out-of-plane and deep puncture needle tip. Due to the lack of clarity of the needle tip position, the distance between the needle tip and the nerve cannot be judged. The needle tip position can be judged only by the diffusion range of local anesthetics, which limits the realization of accurate anesthesia. This disadvantage of ultrasound prompted us to study the combination of tip navigation technology and ultrasound in guiding nerve block. In 2009, Ultrasonix launched an ultrasonic puncture navigation system based on magnetic positioning, which enables puncture at any angle and monitors the position of the needle tip in real-time. This can help to save the puncture time and reduce the puncture risk. Then, Philips launched the threedimensional ultrasonic navigation system G4 xMATRIX iU22 that realized the puncture navigation at any angle in the three-dimensional region and avoided the interference by surrounding organs or blood vessels (Declaration: All authors of this article do not have any conflict of interest with the device manufacturers listed above). ${ }^{32}$ Magnetic positioning is a real-time positioning technique using a nonvisual state based on the ability of magnetic fields to penetrate unshielded objects. It is composed of an electromagnetic field transmitter with a specific coverage and one or more small receivers and microprocessors that can be attached to the probe. The microprocessor is used to control the transmitter's emission of the electric field into space, and the receiver is fixed on the probe and puncture needle. In nerve block puncture, the receiver can sense the coordinate information and orientation information of the probe and puncture needle in three-dimensional space. These two groups of freedom parameters are then stored in the computer. Through post-processing, the position information of the puncture needle can be matched with the position information of the ultrasonic image. ${ }^{33}$ In short, UCOT (magnetic navigation) for guiding nerve block solves the problem of real-time tracking of the needle tip and has broad developmental prospects for future regional block anesthesia.

\section{UCOT (Pressure Guidance)}

Many of the target spaces of regional anesthesia have negative pressure (such as the epidural and thoracic paravertebral spaces). When regional anesthesia puncture is performed by ultrasound combined with pressure monitoring, it is possible to judge when the needle tip reaches the target space by the change of pressure and the position of the needle tip on the ultrasonic image. This technology can increase the puncture success rate. In addition, monitoring pressure changes during puncture can avoid intraneural injection. There has been some research on pressureguided nerve block. ${ }^{34-36}$ Recent studies from our group have attempted to evaluate the value of ultrasound and pressure mediated guidance for thoracic paravertebral block (TPVB) in patients treated by video-assisted thoracic surgery (VATS). ${ }^{37}$ TPVB has traditionally been used for postoperative pain management, relying on factors such as the use of air or loss of resistance with $0.9 \%$ saline to accurately determine anatomical localization. However, a sudden drop in resistance is more subjective for paravertebral space (PVS) navigation. ${ }^{38}$ When the needle tip is in erector spinae muscle, the inspiratory/expiratory pressure reading are higher. The pressure decreased suddenly when the needle tip penetrated the superior costotransverse ligament and into the PVS. These studies suggest that the position of the puncture needle can be indirectly determined by changes in pressure, which further expands the visual measurement range and provides new possibilities for research into ultrasonic guidance nerve block. In the future, more prospective randomized controlled trials targeting UCOT (pressure guidance) are needed to validate the advantages of this novel regional block technique.

\section{UCOT (Video Visualization Guidance)}

Ultrasound is widely used because of its unique advantages. However, ultrasonic images are not real tissue images, so image quality often becomes an important factor limiting its development. There is a constant need for the improvement of ultrasonic image quality. When ultrasonic imaging of the puncture site is blurred due to obesity or trauma, reliable 
image confirmation methods are needed. When the puncture needle or the needle tip cannot be adequately displayed in the ultrasonic image either for out-of-plane or in-plane puncture, reliable image confirmation methods are also needed. This inspired us to develop an UCOT (video visualization guidance) in which ultrasonic guided nerve block is performed under direct video visualization. ${ }^{39,40}$

Video-guided visualization techniques have been widely used in surgical deep tissue manipulation or refined treatment, such as gynecological and general surgery using video-assisted laparoscopy for deep abdominopelvic surgery; thoracic surgery using video-assisted thoracoscopic surgery for pulmonary surgery; urology using ureteroscope to grasp high stones such as renal pelvis and calyces in a small field of view; and spinal surgery using a bore scope for the treatment of intervertebral discs and spinal nerves. In the future, anesthesiologists and pain physicians can also use video-guided visualization techniques for regional anesthesia techniques and treatments such as paravertebral block or fascial compartment block. At present, the aperture endoscope in spinal surgery has been very slender. Whether a thinner aperture endoscope can be inserted into the nerve block needle or radiofrequency puncture needle for regional block or treatment, so that the real-time image and adjacent structures during block can be clearly projected on the television. Combined with the use of ultrasound, the UCOT (video visualization guidance) can be realized to perform the ultrasound-guided nerve block or pain treatment under direct video vision. ${ }^{41,42}$

\section{UCOT (Electromyography (EMG) Guidance)}

Improving the accuracy of puncture needle localization can effectively reduce the risk of complications such as accidental injury to intra-abdominal structures, femoral nerve palsy, or local anesthetic toxicity during abdominal plane block. ${ }^{43}$ EMG is a mode of understanding the electrical activity present within a muscle. ${ }^{44}$ This can be done using surface electrodes, or more precisely, using needle electrodes (called needle EMG) from within the muscle. By using needle EMG, we can obtain the anatomical position and discharge pattern of single muscle fiber and the whole motor unit. The measured potential between the needle and the reference can be shown graphically or transmitted through a speaker with LED display. ${ }^{45}$

Mullins et al 's study ${ }^{46}$ is the first to report the use of needle EMG technique combined with ultrasound localization for quadratus lumborum block for postoperative analgesia in open appendectomy. The needle tip provides useful feedback to the operator as it penetrates the tissue and complements the corresponding ultrasound image so that the exact position of the needle tip can be determined more accurately. Needle EMG techniques have also been used to assist piriformis injection in the treatment of piriformis syndrome. ${ }^{47}$ While the flow of fascial layers during piriformis injection therapy is associated with artifacts on EMG, the resulting associated signals and information can be useful when used in conjunction with ultrasound for these therapies.

Hodes et $\mathrm{al}^{48}$ pioneered studies using electromyography and nerve conduction to assess motor function by the strength of the response to compound muscle action potentials (CMAPs). The study by Qian et al intends to evaluate the efficacy of obturator nerve block by the change of CMAP amplitude of adductor longus muscle. ${ }^{49}$ Because the anterior branch of the obturator nerve innervates the adductor longus muscle, the amplitude of the adductor longus CMAP provides information about the degree to which the motor fibers of the obturator nerve are blocked. $^{50}$ This effectively combines the advantages of EMG and ultrasound, making the position of the puncture needle more accurate and the operation of nerve block safer. In the future, further studies are needed to validate the use of UCOT \& EMG in regional anesthetic techniques and pain treatment.

\section{UCOT (Optical Coherence Tomography (OCT) Guidance)}

Epidural anesthesia is one of the most widely used anesthetic techniques. Due to the lack of real-time navigation and feedback of puncture needles, anesthesiologists often face challenges in the operation of complex patients such as obesity and spinal deformity. In order to solve these problems, ultrasound-guided and fluoroscopic needle insertion is a good method, which can make the operation more accurate. However, these techniques do not provide sufficient contrast and resolution to effectively distinguish the tissue layers through which the needle passes or to specifically identify the epidural space. To accurately identify the epidural space, Tang et $\mathrm{al}^{51}$ invented a small handheld optical coherence tomography (OCT) forward imaging puncture needle device for real-time guidance of epidural anesthesia and demonstrated its feasibility through animal experiments (in vivo and ex vivo) (Figure 2). 


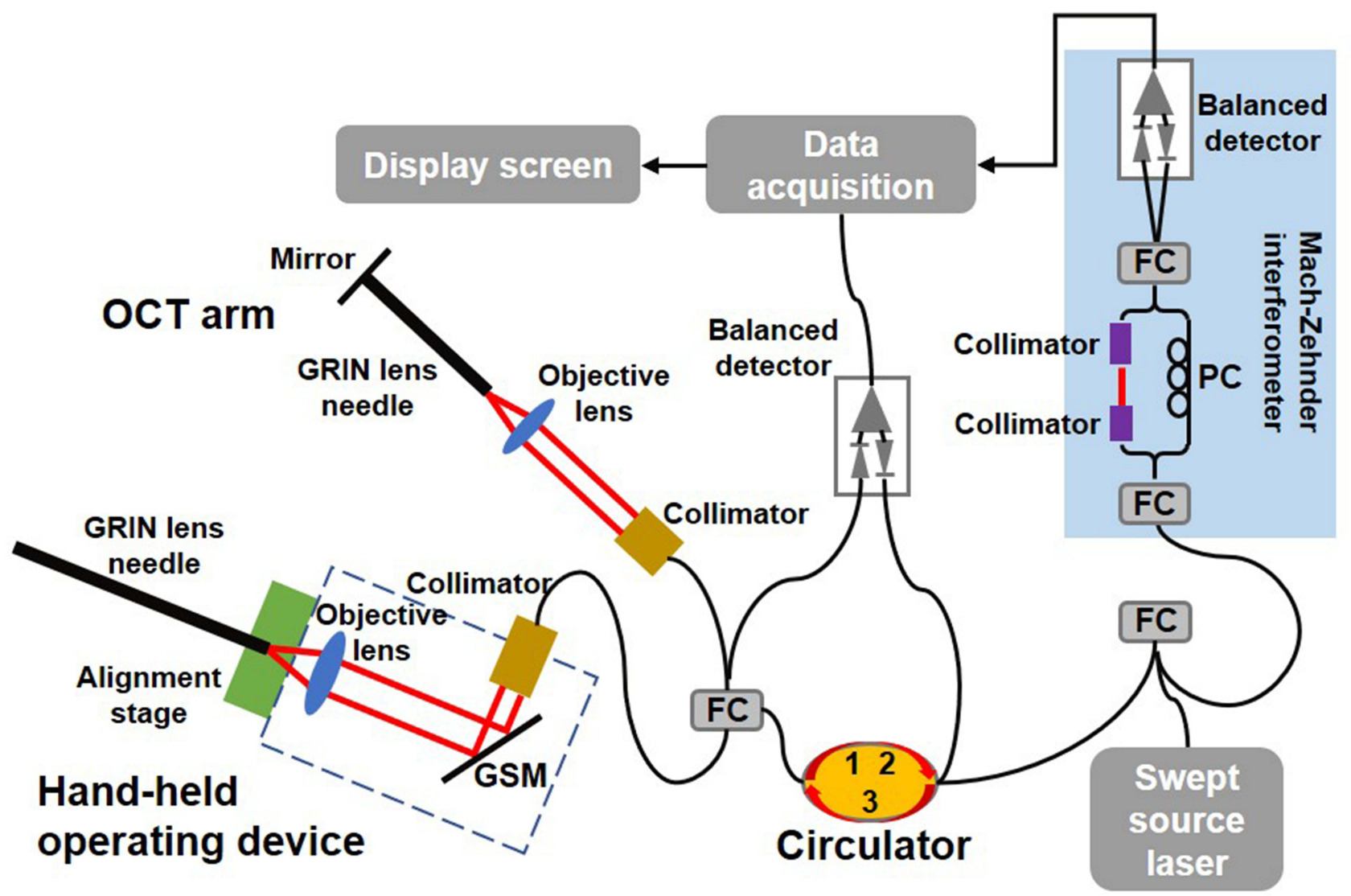

Figure 2 Diagram of hand-held OCT needle imaging system.

Abbreviations: FC, fiber coupler; PC, polarization controller; GSM, galvanometer scanning mirror; OCT, optical coherence tomography; GRIN, gradient-index.

OCT is an ultrasound-based optical simulation technique that provides micron-level imaging resolution, an order of magnitude greater than ultrasound. ${ }^{52}$ Raphael et $\mathrm{al}^{53}$ showed the feasibility of OCT imaging techniques for puncturing structures such as arteries, nerves, and dura mater in ex vivo animal studies. Using the principle of microoptics, OCT technology can be transformed into a small device for needle imaging to assist in minimally invasive procedures. ${ }^{54,55}$ During the experiment, the needle tip of the device was slowly inserted into different layers in the tissue. OCT images corresponding to different anatomical structures were acquired separately during the entire process from the skin to the epidural space. It is not difficult to conclude from the images that there are characteristic differences between different anatomical structures, especially between the ligamentum flavum and the dura membrane or fat. In vivo OCT images clearly show the feasibility of distinguishing anatomical structures and tissue types in real time, therefore, identifying the needle tip position in real time during epidural anesthesia will make the operation more accurate and have lower risks. ${ }^{51}$ OCT needle imaging technology will reduce the incidence of complications, reduce the induction of pain, and the risk of surgical failure by visualizing the needle tip and clarifying the tissue structure where the needle tip is located compared with standard procedures. In addition, this technique can be used in combination with ultrasound/X-ray to achieve precise anesthesia and reduce patient suffering.

\section{UCOT (Al Guidance)}

Due to a lack of experience, it is often difficult for trainee doctors to identify the structure when using ultrasound, especially in obese patients, elderly patients with poor imaging quality, and trauma patients with tissue edema. In these cases, ultrasonic guidance becomes difficult and an AI recognition system is needed for guidance.

AI technology includes features such as neural networks with expert system and pattern recognition. ${ }^{56}$ Neural networks have the advantages of strong learning ability, multi-input, and multi-output. The technology is also easy to implement in terms of hardware and can be effectively combined with medical imaging. Deep learning is an automatic feature extractor, 
which imitates the signal processing process of the human nerve. In the presence of sufficient training data (neural images and expert annotation), it can automatically learn the image features of particular situations through deep learning without the need to design the features artificially. Ultrasound combined with AI has been proved to be more accurate. When the noninvasive liver fibrosis rating system was established using this technique, the accuracy of the trained model reached $88.3 \%$ after evaluation. When the technique was used to classify early-stage benign and malignant thyroid nodules, the accuracy, sensitivity, and specificity of the technique were $82.3 \%, 84.5 \%$, and $79.1 \%$, respectively. ${ }^{57}$ In nerve block anesthesia, nerve performances may differ due to the actual scanning position, image parameters, and patient specificity. Compared with conventional feature extraction methods, the deep learning neural network is more stable and accurate. ${ }^{31}$ This provides us with a new direction of exploration. The AI system can be used to help identify neural structures resulting in improved understanding and interpretation of complex images by junior doctors. The use of UCOT \& AI will have a broader prospect in the future development of regional anesthesia.

\section{UCOT (Image Fusion Guidance)}

Medical image fusion is the spatial registration and superposition of medical images from the same or different imaging methods. The outstanding advantages of CT are high-density resolution, clear sectional anatomical relationships, and good display of lesion details; disadvantages include the use of radiation and large size requiring adequate space. Magnetic resonance imaging (MRI) has the advantage of multiplanar imaging, which compensates for the disadvantages of CT. MRI can display lesions clearly without the interference of bone artifacts and can display the structures of the skull base and spinal canal well. ${ }^{58}$ However, it has the disadvantages of high cost, complex imaging, inconvenience for emergency examination, and inconvenience for fracture observation. Ultrasound has the advantages of convenience, a lack of radiation, and bedside operation. Ultrasound combined with CT and MRI for image fusion can display fine structures that cannot be recognized in ultrasonic images to realize the interventional operation of these fine structures under bedside ultrasonic guidance. $^{59,60}$

The UCOT (image fusion) has been applied in the field of regional anesthesia. Strid et $\mathrm{al}^{61}$ conducted the first randomized controlled trial of ultrasound/MRI fusion for lumbosacral plexus block and confirmed that ultrasound/MRI fusion technology was effective and safe. However, compared with ultrasonic guidance, it requires a longer preparation process. Munirama et $\mathrm{al}^{62}$ proposed a novel image fusion technique composed of ultrasound B mode and elastography to enhance the function of elastography. Through the different imaging modalities, intraneural injection can be observed in an early stage according to the different cross-sectional area and brightness of the nerve, allowing the puncture needle to be withdrawn to avoid possible postoperative nerve injury. This can be used as an important means of real-time monitoring of intraneural injection and can effectively reduce the incidence of intraneural injection. In recent years, many reports have advocated the use of selective nerve root block under CT guidance, which is taking advantage of CT imaging for lumbar applications. However, CT guidance has the disadvantages of high cost and the use of radiation. Study by Li et $\mathrm{al}^{63}$ showed that the number of X-ray fluoroscopy used in fusion imaging was lower than that in ultrasonic guidance alone, which reduced the patients' exposure to radiation. However, the total puncture time in fusion imaging was not statistically different from that using ultrasound alone, which may have been related to the operator's extensive experience in ultrasonic operation. In addition, $\mathrm{Nix}^{64}$ and $\mathrm{Lim}^{65}$ demonstrates the feasibility of $3 \mathrm{D}$ reconstruction techniques in the clinic and the significant promise of the UCOT (image fusion).

\section{Conclusions and Prospects}

In regional anesthesia, none of the currently used guidance methods including ultrasound, neurostimulator, or ultrasound combined with neurostimulator can effectively avoid intraneural injection. Although the ultrasound guidance technique is gaining popularity in the clinic, many questions remain to be addressed regarding the use of ultrasound for deep target block as well as in obese or elderly patients. The UCOT is helpful to solve the difficulty of puncture localization due to a patient's obesity, anatomical variation, and other factors when ultrasound guidance is used alone. In the future, more techniques need to be investigated and developed for ultrasound combinations, to exploit the advantages of ultrasound and remedy its disadvantages.

\section{Acknowledgments}

This work was supported by the Beijing Hospitals Authority Clinical Medicine Development of Special Funding Support (XMLX202106).

\section{Disclosure}

The authors report no conflicts of interest in this work. 


\section{References}

1. Bollini CA, Urmey WF, Vascello L, Cacheiro F. Relationship between evoked motor response and sensory paresthesia in interscalene brachial plexus block. Reg Anesth Pain Med. 2003;28:384-388. doi:10.1016/S1098-7339(03)00218-9

2. Forouzan A, Masoumi K, Motamed H, Gousheh MR, Rohani A. Nerve Stimulator versus Ultrasound-Guided Femoral Nerve Block; a Randomized Clinical Trial. Emergency. 2017;5:e54-e54.

3. Pawa A, El-Boghdadly K. Regional anesthesia by nonanesthesiologists. Curr Opin Anaesthesiol. 2018;31:586-592. doi:10.1097/ACO.0000000000000643

4. Grasso A, Orsaria P, Costa F, et al. Ultrasound-guided Interfascial Plane Blocks for Non-anesthesiologists in Breast Cancer Surgery: functional Outcomes and Benefits. Anticancer Res. 2020;40:2231-2238. doi:10.21873/anticanres.14185

5. Sia S, Bartoli M, Lepri A, Marchini O, Ponsecchi P. Multipleinjection axillary brachial plexus block: a comparison of two methods of nerve localization-nerve stimulation versus paresthesia. Anesth Analg. 2000;91:647-651. doi:10.1213/00000539-200009000-00028

6. Sia S, Lepri A, Campolo MC, Fiaschi R. Four-Injection Brachial Plexus Block Using Peripheral Nerve Stimulator: a Comparison Between Axillary and Humeral Approaches. Anesth Analg. 2002;95:1075-1079.

7. Che X, Liang W, Chen J. Triple-injection Axillary Brachial Plexus Block: a Comparison of Two Nerve-localization Techniques, Nerve Stimulation Versus Paresthesia. Fudan Univ J Med Sci. 2005;529-532+535.

8. Sia S. Axillary brachial plexus block using peripheral nerve stimulator: a comparison between double- and triple-injection techniques. Reg Anesth Pain Med. 2001;26:499-503. doi:10.1053/rapm.2001.25896

9. Urmey WF, Stanton J. Inability to consistently elicit a motor response following sensory paresthesia during interscalene block administration. Anesthesiology. 2002;96:552-554. doi:10.1097/ 00000542-200203000-00008

10. Choyce A. What is the relationship between paresthesia and nerve stimulation for axillary brachial plexus block? Reg Anesth Pain Med. 2001;26:100-104. doi:10.1053/rapm.2001.21740

11. Selander D, Dhunér KG, Lundborg G. Peripheral nerve injury due to injection needles used for regional anesthesia. An experimental study of the acute effects of needle point trauma. Acta Anaesthesiol Scand. 1977;21:182. doi:10.1111/j.1399-6576.1977.tb01208.x

12. Lavoie J, Martin R, Tétrault JP, Côté DJ, Colas MJ. Axillary plexus block using a peripheral nerve stimulator: single or multiple injections. Canadian J Anaesthesia. 1992;39:583-586. doi:10.1007/BF03008322

13. Mulroy MF, Mitchell B. Unsolicited paresthesias with nerve stimulator: case reports of four patients. Anesth Analg. 2002;95:762.

14. Robards C, Hadzic A, Somasundaram L, Iwata T, Gadsden J, Xu D. Intraneural Injection with Low-Current Stimulation During Popliteal Sciatic Nerve Block. Anesth Analg. 2009;109:673-677. doi:10.1213/ ane.0b013e3181aa2d73

15. Sala-Blanch X, López AM, Pomés J, Valls-Sole J, García AI, Hadzic A. No Clinical or Electrophysiologic Evidence of Nerve Injury after Intraneural Injection during Sciatic Popliteal Block. Anesthesiology. 2011;115:589-595. doi:10.1097/ALN.0b013e3182276d10

16. Kirchmair L, Ströhle M, Löscher WN, Kreutziger J, Voelckel WG, Lirk P. Neurophysiological effects of needle trauma and intraneural injection in a porcine model: a pilot study. Acta Anaesthesiol Scand. 2016;60:393-399. doi:10.1111/aas.12657

17. Russon K, Blanco R. Accidental Intraneural Injection into the Musculocutaneous Nerve Visualized with Ultrasound. Anesth Analg. 2007;105:1504-1505. doi:10.1213/01.ane.0000287246.47283.0e

18. Liu SS, YaDeau JT, Shaw PM, Wilfred S, Shetty T, Gordon M. Incidence of unintentional intraneural injection and postoperative neurological complications with ultrasound-guided interscalene and supraclavicular nerve blocks*. Anaesthesia. 2011;66(3):168-174. doi:10.1111/j.1365-2044.2011.06619.x
19. Liu SS, Ngeow JE, YaDeau JT. Ultrasound-Guided Regional Anesthesia and Analgesia. Reg Anesth Pain Med. 2009;34:47-59. doi:10.1097/AAP.0b013e3181933ec3

20. Neal JM, Brull R, Chan VWS, et al. The ASRA Evidence-Based Medicine Assessment of Ultrasound-Guided Regional Anesthesia and Pain Medicine. Reg Anesth Pain Med. 2010;35:S1-S9. doi:10.1097/ AAP.0b013e3181d22fe0

21. Chin KJ, Perlas A, Chan VW, Brull R. Needle visualization in ultrasound-guided regional anesthesia: challenges and solutions. Reg Anesth Pain Med. 2008;33:532-544. doi:10.1016/j.rapm.2008.06.002

22. Xu C, Zheng Y, Zhang W, Yang Q, Wang H, Wang G. The clinical efficacy of bilateral axillary brachial plexus block guided by ultrasound or neurostimulator. J China Japan Friendship Hospital. 2018;11-14.

23. He D, Jia D, Guo X. Analgesic Effects of Ultrasonography Combined with Nerve Stimulation Guidance for Continuous Femoral Nerve Block after Total Knee Arthroplasty. Chin J of Min Inv Surg. 2011;11:304-307.

24. Li H, Zhang H, Wang Y. Ultrasound-guidance improves accuracy in locating interscalene for brachial plexus nerve blocking in obese patients. Int J Anesth Resus. 2017;38:983-986.

25. Candido K. Buprenorphine added to the local anesthetic for brachial plexus block to provide postoperative analgesia in outpatients. Reg Anesth Pain Med. 2001;26:352-356. doi:10.1053/rapm.2001.23931

26. Vester-Andersen T, Husum B, Zaric D, Eriksen C. Peri vascular axillary block VII: the effect of a supplementary dose of $20 \mathrm{~mL}$ mepivacaine $1 \%$ with adrenaline to patients with incomplete sensory blockade. Acta Anaesthesiol Scand. 1986;30:231-234. doi:10.1111/ j.1399-6576.1986.tb02403.x

27. Barrington MJ, Watts SA, Gledhill SR, et al. Preliminary Results of the Australasian Regional Anaesthesia Collaboration. Reg Anesth Pain Med. 2009;34:534-541. doi:10.1097/AAP.0b013e 3181ae72e8

28. Tsui BCH, Pillay JJ, Chu KT, Dillane D. Electrical Impedance to Distinguish Intraneural from Extraneural Needle Placement in Porcine Nerves during Direct Exposure and Ultrasound Guidance. Anesthesiology. 2008;109:479-483. doi:10.1097/ALN.0b013e318182c288

29. Hadzic A, Dilberovic F, Shah S, et al. Combination of intraneural injection and high injection pressure leads to fascicular injury and neurologic deficits in dogs. Reg Anesth Pain Med. 2004;29:417-423. doi:10.1016/j.rapm.2004.06.002

30. Kapur E, Vuckovic I, Dilberovic F, et al. Neurologic and histologic outcome after intraneural injections of lidocaine in canine sciatic nerves. Acta Anaesthesiol Scand. 2007;51:101-107. doi:10.1111/ j.1399-6576.2006.01169.x

31. Bernards C, Hadzic A, Suresh S, Neal J. Regional Anesthesia in Anesthetized or Heavily Sedated Patients. Reg Anesth Pain Med. 2008;33:449-460. doi:10.1097/00115550-200809000-00008

32. Tang Y. Research on Real-time Medical Ultrasound Navigation and Soft Tissue Modeling. Zhejiang Univ. 2012.

33. Xu Q, Chen R, Xiong J, Cai N, Zhang Y. Exploratory research on Wiguide needle guidance ultrasound technology for radial artery puncture. Chin J Ultrasonogr. 2019;28:794-797.

34. Tsui BCH, Li LXY, Pillay JJ. Compressed air injection technique to standardize block injection pressures. Canadian $J$ Anesthesia. 2006;53:1098-1102. doi:10.1007/BF03022877

35. Claudio R, Hadzic A, Shih H, et al. Injection pressures by anesthesiologists during simulated peripheral nerve block. Reg Anesth Pain Med. 2004;29:201-205. doi:10.1016/j.rapm.2003.12.013

36. Gadsden JC, Choi JJ, Lin E, Robinson A. Opening Injection Pressure Consistently Detects Needle-Nerve Contact during Ultrasoundguided Interscalene Brachial Plexus Block. Anesthesiology. 2014;120:1246-1253. doi:10.1097/ALN.0000000000000133

37. Li H, Wei H, Ma D, Wang Y. Ultrasound and pressure-guided thoracic paravertebral block. Eur J Anaesthesiol. 2020;37:824-826. doi:10.1097/EJA.0000000000001198 
38. Naja Z, Lonnqvist P. Somatic paravertebral nerve blockade Incidence of failed block and complications. Anaesthesia. 2001;56:1181-1201. doi:10.1046/j.1365-2044.2001.02084.x

39. Woodworth GE, Chen EM, Horn JE, Aziz MF. Efficacy of computer-based video and simulation in ultrasound-guided regional anesthesia training. J Clin Anesth. 2014;26:212-221. doi:10.1016/j. jclinane.2013.10.013

40. Udani AD, Harrison TK, Howard SK, et al. Preliminary study of ergonomic behavior during simulated ultrasound-guided regional anesthesia using a head-mounted display. $J$ Ultrasound Med. 2012;31:1277-1280. doi:10.7863/jum.2012.31.8.1277

41. Kasuya Y, Moriwaki S, Inano C, Fukada T, Komatsu R, Ozaki M. Feasibility of the head-mounted display for ultrasound-guided nerve blocks: a pilot simulator study. $J$ Anesth. 2017;31:782-784. doi:10.1007/s00540-017-2371-x

42. Wu Z, Wang Y. Research progress in anatomy of abdominal fascial space and related regional anesthesia techniques. Int J Anesth Resus. 2020;41:794-799.

43. El-Dawlatly AA, Turkistani A, Kettner SC, et al. Ultrasound-guided transversus abdominis plane block: description of a new technique and comparison with conventional systemic analgesia during laparoscopic cholecystectomy $\dagger$. Br J Anaesth. 2009;102:763-767. doi:10.1093/bja/aep067

44. Feinstein B, Pattle RE, Weddell G. Metabolic factors affecting fibrillation in denervated muscle. J Neurol Neurosurg Psychiatry. 1945;8:1-11. doi:10.1136/jnnp.8.1-2.1

45. Whittaker RG. The fundamentals of electromyography. Pract Neurol. 2012;12:187-194. doi:10.1136/practneurol-2011-000198

46. Mullins CF, O'Brien C, O'Connor TC. Novel use of combination of electromyography and ultrasound to guide quadratus lumborum block after open appendicectomy. BMJ Case Rep. 2017;2017:bcr-2017-219680.

47. Fishman SM, Caneris OA, Bandman TB, Audette JF, Borsook D. Injection of the piriformis muscle by fluoroscopic and electromyographic guidance. Reg Anesth Pain Med. 1998;23:554-559. doi:10.1016/s1098-7339(98)90080-3

48. Hodes R. THE HUMAN ELECTROMYOGRAM IN RESPONSE TO NERVE STIMULATION AND THE CONDUCTION VELOCITY OF MOTOR AXONS. Arch Neurol Psychiatry. 1948;60:340. doi:10.1001/archneurpsyc.1948.02310040011002

49. Qian Y, Guo Z, Huang J, et al. Electromyographic Comparison of the Efficacy of Ultrasound-guided Suprainguinal and Infrainguinal Fascia Iliaca Compartment Block for Blockade of the Obturator Nerve in Total Knee Arthroplasty. Clin J Pain. 2020;36:260-266. doi:10.1097/ AJP.0000000000000795

50. Yoshida T, Nakamoto T, Kamibayashi T. Ultrasound-Guided Obturator Nerve Block: a Focused Review on Anatomy and Updated Techniques. Biomed Res Int. 2017;2017:1-9. doi:10.1155/2017/7023750

51. Tang Q, Liang C, Wu K, Sandler A, Chen Y. Real-time epidural anesthesia guidance using optical coherence tomography needle probe. Quant Imaging Med Surg. 2015;5:118-124. doi:10.3978/j. issn.2223-4292.2014.11.28

52. Wang RK. Optical Microangiography: a Label-Free 3-D Imaging Technology to Visualize and Quantify Blood Circulations Within Tissue BedsIn Vivo. IEEE J Selected Topics Quantum Electronics. 2010;16:545-554. doi:10.1109/JSTQE.2009.2033609

Journal of Pain Research

\section{Publish your work in this journal}

The Journal of Pain Research is an international, peer reviewed, open access, online journal that welcomes laboratory and clinical findings in the fields of pain research and the prevention and management of pain Original research, reviews, symposium reports, hypothesis formation and commentaries are all considered for publication. The manuscript

Submit your manuscript here: https://www.dovepress.com/journal-of-pain-research-journal
53. Raphael DT, Yang C, Tresser N, Wu J, Zhang Y, Rever L. Images of Spinal Nerves and Adjacent Structures With Optical Coherence Tomography: preliminary Animal Studies. J Pain. 2007;8:767-773. doi:10.1016/j.jpain.2007.04.006

54. Han S, Sarunic MV, Wu J, Humayun M, Yang C. Handheld forward-imaging needle endoscope for ophthalmic optical coherence tomography inspection. J Biomed Opt. 2008;13:020505. doi:10.1117/ 1.2904664

55. Liang C, Wierwille $\mathrm{J}$, Moreira $\mathrm{T}$, et al. A forward-imaging needle-type OCT probe for image guided stereotactic procedures. Opt Express. 2011;19:26283. doi:10.1364/OE.19.026283

56. Wang Q, Shen X. Research and Application of Ultrasonic Testing Techniques. J Shanghai Ins Tech. 2013;13:49-53.

57. Liu R, Xia Y, Jiang Y. Application of Artificial Intelligence in Ultrasound Medicine. Med J PUMCH. 2018;9:453-457.

58. Lindseth F, Kaspersen JH, Ommedal S, et al. Multimodal image fusion in ultrasound-based neuronavigation: improving overview and interpretation by integrating preoperative MRI with intraoperative 3D ultrasound. Comput Aided Surg. 2003;8:49-69. doi:10.3109/ 10929080309146040

59. Schlaier JR, Warnat J, Dorenbeck U, Proescholdt M, Schebesch KM, Brawanski A. Image fusion of MR images and real-time ultrasonography: evaluation of fusion accuracy combining two commercial instruments, a neuronavigation system and a ultrasound system. Acta Neurochirurgica. 2004;146:271-277. doi:10.1007/s00701-003-0155-6

60. Ewertsen C, Henriksen BM, Torp-Pedersen S, Nielsen MB. Characterization by Biopsy or CEUS of Liver Lesions Guided by Image Fusion between Ultrasonography and CT, PET/CT or MRI. Ultraschall in Med. 2011;2011(32):191-197. doi:10.1055/s-00291245921

61. Strid JMC, Pedersen EM, Al-Karradi SNH, et al. Real-Time Ultrasound/MRI Fusion for Suprasacral Parallel Shift Approach to Lumbosacral Plexus Blockade and Analysis of Injectate Spread: an Exploratory Randomized Controlled Trial. Biomed Res Int. 2017;2017:1-12. doi:10.1155/2017/1873209

62. Munirama S, Zealley K, Schwab A, et al. Trainee anaesthetist diagnosis of intraneural injection - a study comparing B-mode ultrasound with the fusion of B-mode and elastography in the soft embalmed Thiel cadaver model. Br J Anaesth. 2016;117:792-800. doi:10.1093/ bja/aew337

63. Li Z, Cui L, Li S, Jia D, Jia J, Wang J. Fusion of Real-time US with CT Images Guided Selective Lumbosacral Nerve Root Injection in Lumbar Radiculopathy Patients. Chinese $J$ Ultrasound Med. 2017;33:456-458.

64. Nix CM, Margarido CB, Awad IT, et al. Review of the evidence for teaching ultrasound-guided regional anesthesia. Reg Anesth Pain Med. 2013;38:471-480. doi:10.1097/AAP.0b013e3182a4ed7a

65. Lim MW, Burt G, Rutter SV. Use of three-dimensional animation for regional anaesthesia teaching: application to interscalene brachial plexus blockade †. Br J Anaesth. 2005;94:372-377. doi:10.1093/ bja/aei060

management system is completely online and includes a very quick and fair peer-review system, which is all easy to use. Visit http:// www.dovepress.com/testimonials.php to read real quotes from published authors. 